\title{
Influences of Experiential Pursuing Tendency in Experience Perception with the Moderating Role of Expertise and Demographics $^{1}$
}

\author{
Buntae Kim ${ }^{\text {** }}$ \\ ${ }^{a}$ Associate Professor, Division of Business Administration, Dongseo University, Busan, South Korea, Phone: +821035097329 \\ *Corresponding author's email address: kimbuntae@gdsu.dongseo.ac.kr
}

\section{A R T I C L E I N F O}

Received: 12-11-2016

Accepted: 18-11-2016

Available online: 25-11-2016

Keywords:

Consumption expertise;

Experience perception;

Experiential pursuing tendency.

JEL Classification :

M31, P46.

\begin{abstract}
A B S T R A C T
This study examines the relationship of consumers' experiential pursuing tendency and experience perception with the moderating role of consumers' expertise and their demographics, sex and age. Experience pursuing tendency is based on an individual personality. Experience perception is individuals' affection in the procession of consumption or after purchase. The study found that there are relationships between consumers' experience pursuing tendency and experience perception, sensual, affective consumers perceived even more emotional dimensions of experience. Whereas the other side of consumers, the pursuers more practical are less susceptible to emotional experience and more to professional experience. Accumulated knowledge by indirect learning or directly by oneself does not control the relationship between experiential pursuing tendency and experience perception. But sex and age among demographics are involving the relationships between them. Aged consumers over 50s perceived experience less, especially to the emotional side of experience perception. Finally, managerial and research implications are presented from the results of the study.
\end{abstract}

This is an open access article under the terms of the Creative Commons Attribution License 4.0, which allows use, distribution and reproduction in any medium, provided the original work is properly cited.

DOI: http://dx.doi.org/10.18533/rss.v1i10.76

ISSN : 2378-8569(Print), ISSN 2378-8550(Online)

\subsection{Introduction}

The competitions of corporations or brands need transmitting something integrated over through brands. Specially, it rises increasingly that consumers make decision of purchase at the point of purchase and respond more to various sensual features of purchasing circumstances. Companies use successful consumers' experience on purchasing point as a marketing strategic factor to take competitive advantage of brand. Therefore, consumers are getting recognition more a series of process of consumers' experience in the purchasing circumstance as a substance of integrated brand. Now companies perform their marketing actions for consumers to get experienced. Experience itself features complex activities including more pleasant elements and puts stress on communication process comparing to previous marketing activities. Mobile and online instruments convey companies' these activities rapidly and generally. Various studies performed by corporations and marketing researchers have done on these issues reflecting the trend that consumers' experience on brands, corporations and other factors of them in the point of purchase (Mehmetoglu 2012; Srinivasan \& Srinivasan 2010; Corporate Univ. Review 2001; Pine \& Gilmore 1999).

\footnotetext{
1 This work was supported by the National Research Foundation of Korea Grant funded by the Korean Government (NRF-
} 2013S1A2A1A01034468), This work was also supported by the special grant funded by Dongseo University in 2016. 
Experience is relevant to a specific segmentation on high level of identical consumers' needs. That is, consumers' experience is related to consumers' psychological and physical features by nature. For that reason, how well to fulfill the need is the matter that how much to get close or understand consumer's experience. People show different responses to various stimulus depending on their subculture even in the same situation, representatively on demographics. Sex and age specialize consumers' needs and responses.

Thus this study aims to identify the relationship of consumers' experience pursuing tendency and experience perception and moderating roles of consumers' consumption expertise and demographics to the relationship. Following the results, theoretical and practical implications will be presented.

\section{$2.0 \quad$ Theoretical background}

\subsection{Consumers' pursuing behaviors}

Experience pursuing tendency is a kind of consumer's internal characteristics. Many consumer behavior researches have been studied on this subject. Affective states, symbolic tendency, variety seeking and sensation seeking are the related concepts to experience tendency. They are in somewhat different but here considered and explained similarly.

Personality affects experiential consumption. Mehmetoglu (2012) tried to prove the relationship between personality and experiential consumption. Experiential consumption has been predicted by personality variables, 'The Big Five'. He identified the relationship of personality of five categories and aspects of experiential consumption. Sensual seeking tendency is identified as tendency that consumers seek stimulation to sustain ideal stimulation level to solve the internal or psychological conflicts (McDaniel \& Zukerman 2003). Consumers seeking sensual stimulation try to seek for pleasant actions, but do not have clear purpose for the behavior on doing the seeking behaviors. Sensual seeking behavior is influenced by their internal moods, arousal and sensual stimulations. Stimulation holds in nature novelty, change, astonishment, discordance, complexity, uncertainty or conflict. Individual consumers have potential chance to be awakened by these stimuli.

Similarly, Mehmetoglu (2012), McDaniel \& Zukerman(2003), and Pizam, Reichel \& Uriely (2002) pointed out that sensation seeking behavior is associated with highly impulsivity, novelty and active participation. They concluded high sensation seekers would prefer to travel to exotic places by themselves or without any other prior planning, sensation seekers with low degree would like to take a trip to familiar places in group that is preplanned. They don't want to face unexpected events. High pursuers of experience prefer the process of behavior rather than the behavior itself (Zukerman 1979; Mehrabian \& Russell 1974). Risk taking can be understood as individuals' need for high sensation, like extreme consumption (Zuckerman 1974). With doing risk taking behavior such as taking drugs, smoking, and sports with high risk, people finally get the affect which might be such a special state of affect, dominance. Dominance is coming from individuals' state as an outcome at any given time(Kerr 1991). Consumers seeking for sensation vary on the levels of need for novelty, thrills or adventures. Risk taking activities and experiences satisfy the needs of feeling or affection (Zuckerman 1984). Due to the supposition that different individuals have various levels of need for sensation, sensation seeking is based on personality, personal traits. Though an individual's need for sensation seeking is fairly stable but the level tends to change slowly. Consumers vary on their experiential pursuing tendency but individual's need for this is stable. As time goes on, individual's need for experiential tendency would be changing and the speed and width of change is going to be different following the circumstances and its impact for them. Zuckerman (1984) pointed out sensation seeking into four dimensions, boredom susceptibility, disinhibition, experience seeking, and thrill and adventure seeking.

\begin{tabular}{|c|c|}
\hline \multicolumn{2}{|r|}{ Table 01: Studies on Experience pursuing tendency } \\
\hline Authors & Contents \\
\hline Mehmetoglu (2012) & $\begin{array}{l}\text { Personality and Demographic variables effect on experiential consumption } \\
\text { (consumption categories) }\end{array}$ \\
\hline Noh \& Kim (2002) & - Stimulus Pursuit Tendency \& Ego Identity effect on Attitude \\
\hline $\begin{array}{l}\text { Hoolbrook \& Hirschman } \\
\text { (1982) }\end{array}$ & $\begin{array}{l}\text { Experiential view instead of information-processing model. The one involves a } \\
\text { steady flow of fantasies, feelings, and fun encompassed by what it is called } \\
\text { 'experiential view'. }\end{array}$ \\
\hline $\begin{array}{l}\text { Zuckerman \& Neeb } \\
(1980)\end{array}$ & - Demographic variables, sensation seeking, sensation seeking areas \\
\hline
\end{tabular}

Sensation seeking has been used in marketing studies, most notably in the study of optimal stimulation levels. It has been reported that the higher an individual's deficiency or surplus of stimulation the stronger the action that 
the individual will take to increase or decrease the level of stimulation in one's environment (Wahlers and Etzel 1990).

\subsection{Consumption expertise and demographic characteristics}

Individuals' internal characteristics are defined as knowledge which has been formed by their voluntary or involuntary efforts and experiences. When the same sorts of experience repeat indirectly or directly and voluntary or involuntary, it becomes knowledge that later extends to many sides by the interaction of other cues of memory.

Rosa \& Malter (2003) considered that personal knowledge is stored in memory. But knowledge acquired through indirect contact such as mass media, books would be formed by different types of thinking which are connected each other. They considered a certain object as something or relationship of concepts. When the consumption action is functional or rational, this kind of knowledge helps better to infer educational contents or quality superiority. Experts with this sort of knowledge are doing well in complex thinking. They are well persuaded and trust the people with this kind of rational thinking (Bei \& Widdows 1999). Expertise is the ability to perform product related tasks successfully (Alba \& Hutchinson 1987). Education involves the imparting and acquiring of general knowledge and the development of reasoning and judgment. Education is intendedly didactic, while experience is not. But complex thinking is far from to explain or understand delicate fine points which are related to specific emotions. Adversely, knowledge of direct experience is created and sustained with the procession over intelligence. The knowledge acquired by direct contacts or actual similarly simulated environments is more live and trustful. Personal experience, unlike information delivered by third parties, has that fresh, unvarnished realism that draws us in. Education is pallid while experience is vivid (Hoch 2002). Knowledge by physical senses accompanies aesthetic feeling, pleasure. Sensual products will be felts emotionally with sensual stimulation. In involving direct participation, visit or experience of a process, a place, or an object, consumers get this kind of knowledge and they believe what they saw or experienced. As a result, the knowledge entails aggressive action like performing the action related to previous one next or informing what they have known through the action to other consumers and so on(Neuborne 2001).

Familiarity is the number of product related experiences, accumulated by the consumer (Alba and Hutchinson 1987). Although familiarity may be necessary for the development of expertise, it surely is not sufficient (Alba and Hutchinson, 1987). Hoch (2002) dealt with experience as familiarity compared to actual product knowledge. He pointed out personal experience is overrated. People find it more compelling than they should. In many consumption situations, people are too trusting of what they have learned through experience, seduced by the very real nature of an ongoing stream of activity. They believe they have learned more from product experience than they actually have, trusting themselves more than partisan marketing sources. And people are not adapted for recognizing diagnosis of their consumption experiences, confusing familiarity with actual product knowledge.

Sex is the most powerful demographic variable influencing sensation seeking. Age is also a powerful influence although both of these variables exert their strongest influence on the behavior(Zuckerman and Neeb 1980). Educational and occupational status of subjects, regions even parents related demographics could be regarded as the influencing sources of sensation seeking or experience behavior. And they can be made certain as factors of influencing experience behaviors in various ways. But sex and age affect dominantly deep in experience perception. It is possible that cultural differences between sex and age might play main roles in distinction of consumers' seeking tendency. Sex or age may tend to foster social approval of a sensation seeking trait in males of sex and younger ages but disapproval of the same trait in females or the other age groups. They suggested that such polarization of sex roles is more common in less educated and lower socioeconomic families, then women coming from such social backgrounds would be more prone to suppress the expressions of the trait in themselves than would all men and women from high socioeconomic background (Zuckerman \& Neeb 1980). Srinivasan and Srivastavan (2010) showed Y generation has a distinct personality and behave differently in malls comparing to other generations.

\section{$2.3 \quad$ Experience perception}

Experience is defined as the act of living through and observation of events and also referred as training and the subsequent knowledge or skill acquired (Hoch 2002). Schmitt (1999) contrasted traditional marketing of product oriented focus on functional features and benefits with experience marketing of customer oriented focus on experiences. Experience does not presume a motivational state. Experiences can happen when consumers do not show interest in or have a personal connection with the brand. Experience also differs from the effect of strong emotional bonds between a consumer and a brand (Thomson et al., 2005). In contrast to brand attachment, which often evokes strong emotions, experience is not merely an emotional relationship concept. Most experiences also include ordinary sensations, feelings, cognitions, and behavioral responses evoked by brand related stimuli. 
Mehmetoglu (2012) regarded experience consumption as opposite side to sensation seeking behavior. That is, he sees experiential consumption encompasses activities that may contain a low degree of impulsivity, novelty and active participation (Pizam, Reichel \& Uriely 2002) rather than sensation seeking behavior. Upon his view on experience perception, sensation seeking behavior is part of experiential consumption. Personality is a salient predictor of experiential consumption (Mehmetoglu 2012; Holbrook \& Hirschman 1982).

\section{Research design}

\subsection{Research model and propositions}

This study sets up the research model on the basis of the previous theoretical studies. The propositions are followed on the relationships between variables composing of the research model. The purpose of empirical test is to verify the research propositions.

Figure 01: Research Model

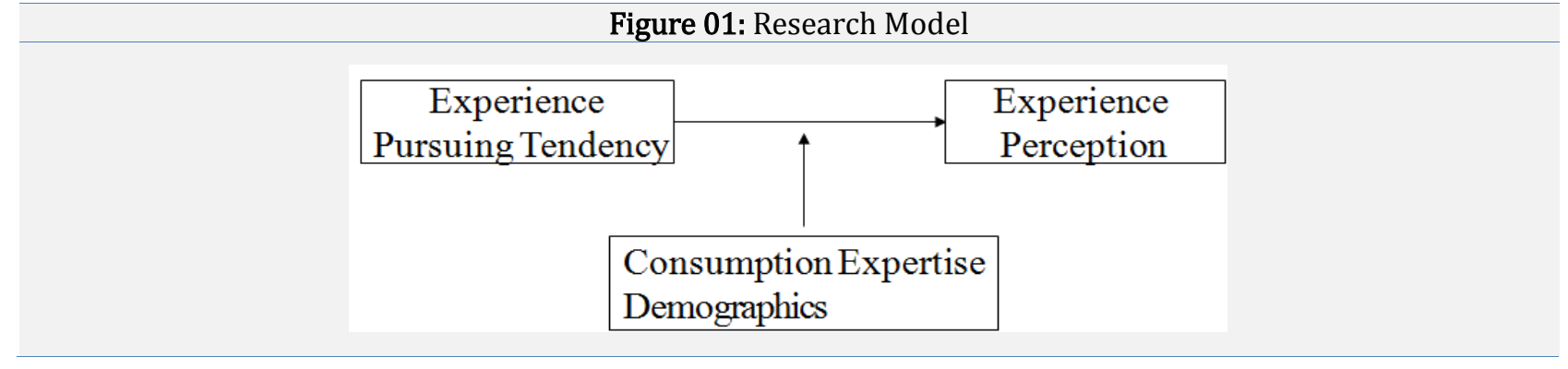

Table 02: Research propositions

Proposition 1: Does Experience pursuing tendency have effects on Experience perception after product consumption?

Proposition 2: Does consumer Expertise make differences on the relationship of Experience pursuing tendency and Experience perception?

Proposition 3: Do Demographics, Sex and Age make differences on the relationship of Experience pursuing tendency and Experience perception?

\subsection{Research method and measurement}

The psychometric properties of the scale have been examined in consumer marketing research. The scale used here have been studied through previous research' reliability and convergent validity to be acceptable. Sensation seeking, risk taking, variety seeking and other experience seeking behavior would be relevant to experience pursuing tendency. For the study, experience pursuing tendency is identified as tendency to participate direct contact to improve or sustain internal level of arousal. Here, items to measure experience pursuing tendency were chosen from the studies already tested and applied to this study's purpose.

The 4 items were used they are initiative to follow new trend or newness, preference for sensory stimulations, persistence to usual life, and avoidance to change surrounding circumstances (Zuckerman, Buchsbaum \& Murphy 1980; Zukerman 1979: Mehrabian \& Russell 1976). Each item was asked from low(1) to high(5) with Likert 5 interval scale.

Experience perception is defined as consumers' internal acceptance or recognition of what they experienced. Though they experienced same thing, circumstance or person, perception or acceptance would be depending on a consumer. Therefore experience perception would be better concept than experience that many of other studies use the word with similar meaning. 18 items were asked which are drawn from the studies on this subject. Each item was asked from low(1) to high(5) with Likert 5 interval scale.

Consumer expertise is the experience accumulated directly or indirectly on a consumption object, a product or a service, or a place and so on. Specifically it could be generally separated into two sides. One acquired directly, the other indirectly that is the first, embodied knowledge, the second, conceptual knowledge. Embodied knowledge was measured as numbers of direct experience. 5 categories of 1 to over 5 were checked. Conceptual knowledge was measured by degrees of indirect experiences that is subjective evaluation on the related experience with 3 items of Likert 5 interval scale. 
Sex and Age are used as demographic variables. Age is separated to 5 areas from 10 s to over 50 s of which the division is judged to show lifestyle differences between and get answers more clearly.

Table 03: Variable Measurement

Variables Measurement

- initiative to follow new trend or newness such as fashion, technology, instrument with new functions(SEN1)

- preference for sensory stimulations such as activities of sports, plays, actions,

experience

pursuing

tendency

hobbies of listening music, looking for arts(SEN2)

- persistence to usual life, not looking for different or sensational happenings or events(PRA1)

- avoidance to change surrounding circumstances such as change house interior decorations, move to new house or other place or participation in a group newly(PRA2)

the thing used or the place visited is playful(EXP1)

the thing used or the place visited has well decorated interior(EXP2)

the thing used or the place visited is looking good(EXP3)

the thing used or the place visited has its own pleasure(EXP4)

the thing used or the place visited gives me time spend efficiently(EXP5)

the thing used or the place visited needs rational spending generally(EXP6)

the thing used or the place visited makes me immerse in and forget things from daily life(EXP7)

the thing used or the place visited gets me know things new or newly(EXP8)

the thing used or the place visited has expertise or professionalism(EXP9)

the thing used or the place visited has me different experience away from daily

experience perception life(EXP10)

the thing used or the place visited seems to induce me to meet or visit again and makes me feel passion and freedom(EXP11)

the thing used or the place visited makes me experience different world(EXP12)

the thing used or the place visited makes me use or meet itself again even without any buying it(EXP13)

the thing used or the place visited gives superiority or dominant excellence(EXP14) the thing used or the place visited is worthy and valuable(EXP15)

the thing used or the place visited is providing product, service or things and also gives pleasure (EXP16)

the thing used or the place visited displayed well and attractively and serviced attractively too(EXP17)

the thing used or the place visited is meaningful(EXP18)

degree of knowledge about the types of a product, a service, or a place(KNO1)

consumption expertise degree of ability to use a product, a service or a place as it supposed to be expertise used(KNO3)

embodied numbers of direct experience of a product, a service, a store or a place which is most expertise special in memory within 3 months

$\begin{array}{lll}\text { demographics } & \text { sex } & \text { male, female } \\ & \text { age } & 10 \mathrm{~s} \sim \text { over } 50 \mathrm{~s}\end{array}$

\subsection{Results}

\subsection{Reliability and validity}

This research aims to identify the relationships of experience pursuing tendency and experience perception and the role of expertise and sex and age, demographics as moderators of the relationships. Experience pursuing tendency is the internal feature among personal traits in specific situation of purchasing or consumption. For the investigation of the variables' relationships, research survey from questionnaire was conducted and the data collected from the survey was analyzed. 
As looking at the sample characteristics, males are 164(56.3\%), females are 211(56.3\%), 20s' group in age is the biggest $(176,46.9 \%)$ that charges students in occupations $(35.2 \%)$, their income might be positioned to under 1 million won(41.9\%). This might be from the reason that students or under 20s are more likely to answer actively to survey. The 390 respondents participated to the survey request with random convenient sampling. The 375 responses were used for the analysis with the deletion of few responses not properly answered. Survey was held in supermarkets, banks, (amusement) parks, museums, in various places of main cities in Korea. Respondents generally represent a population.

\begin{tabular}{|c|c|c|c|}
\hline \multicolumn{4}{|c|}{ Table 04: Sample's characteristics } \\
\hline Items & Types & Frequency & Ratio(\%) \\
\hline \multirow{2}{*}{ sex } & male & 164 & 43.7 \\
\hline & female & 211 & 56.3 \\
\hline \multirow{5}{*}{ age } & $10 \mathrm{~s}$ & 15 & 4 \\
\hline & $20 s$ & 176 & 46.9 \\
\hline & $30 s$ & 76 & 20.3 \\
\hline & $40 \mathrm{~s}$ & 63 & 16.8 \\
\hline & over 50 s & 45 & 12.0 \\
\hline \multirow{6}{*}{ income } & less than 1 million won & 157 & 41.9 \\
\hline & 1 million less than 3 million won & 144 & 38.4 \\
\hline & 3 million $\sim$ less than 5 million won & 56 & 14.9 \\
\hline & 5 million $\sim$ less than 8 million won & 8 & 2.1 \\
\hline & 8 million $\sim$ less than 1 billion won & 9 & 2.4 \\
\hline & over 1 billion won & 1 & .3 \\
\hline \multirow{8}{*}{ occupation } & student & 132 & 35.2 \\
\hline & housekeeper & 50 & 13.3 \\
\hline & manager or technician & 38 & 10.1 \\
\hline & office worker & 61 & 16.3 \\
\hline & self-employed & 30 & 8.0 \\
\hline & sales or service & 44 & 11.7 \\
\hline & no jobs & 6 & 1.6 \\
\hline & etc & 13 & 3.5 \\
\hline Total & & 375 & 100 \\
\hline
\end{tabular}

Factor analysis was conducted to verify variables' constructs. The principal component analysis of factor extraction method and varimax rotation was used. All factors were found with the basis of Igen value 1 , with the deletion of items which have defection for validity. $<$ Table $05>$ shows the results. Finally the variable, experience pursuing tendency composed of 2 factors, The variable, experience perception was extracted into 4 factors. A part of consumption expertise, indirect experience of 3 items fell into one factor. On doing the analysis, each item in the factors was loaded over .7, community is over .6, total variance over $60 \%$. Therefore the items classified were similar within the factor but different from across the other factors.

Reliabilities show all measurements for constructs are reliable with the values of Cronbach`s $\alpha$, more than .7.

\begin{tabular}{lllrr}
\hline \multicolumn{5}{c}{ Table 05: The Results of Reliabilities and Validity } \\
\hline Variables & & Items & $\begin{array}{r}\text { Standardized } \\
\text { Factor Loadings }\end{array}$ & $\begin{array}{r}\text { Cronbach's } \\
\text { Alpha }\end{array}$ \\
\hline \multirow{2}{*}{$\begin{array}{l}\text { experience } \\
\text { pursuing }\end{array}$} & factor 1: & SEN1 & .86 & .82 \\
tendency & factor 2: & SEN2 & .90 & .85 \\
& pragmatic tendency & PRA1 & .82 & .82 \\
\hline
\end{tabular}




\begin{tabular}{|c|c|c|c|c|}
\hline & & EXP1 & .80 & \\
\hline & factor 1: pleasure & EXP4 & .83 & .73 \\
\hline & & EXP5 & .78 & \\
\hline & factor 2. aesthetic & EXP2 & .89 & 75 \\
\hline & Iactor L. aestinetic & EXP3 & .89 & \\
\hline & & EXP8 & .69 & \\
\hline perception & factor 3. suneriority & EXP9 & .67 & 69 \\
\hline & Iactor 3: superiority & EXP14 & .78 & .69 \\
\hline & & EXP15 & .73 & \\
\hline & & EXP7 & .78 & \\
\hline & factor 4 : & EXP10 & .83 & 84 \\
\hline & escape & EXP11 & .83 & .84 \\
\hline & & EXP12 & .85 & \\
\hline & & KNO1 & .81 & \\
\hline consumption & conceptual & KNO2 & .83 & .74 \\
\hline & Knowleage & KNO3 & .80 & \\
\hline
\end{tabular}

\subsection{Experience pursing tendency and experience perception}

Before regression analyses, multicollinearity between variables was checked. Tolerance and VIF(Variance Inflation Factor) were over .1 and under 10 respectively which are the limits of the values. Therefore variables for regression analyses are allowed for use.

Two factors extracted from factor analysis on Experience pursuing tendency were named 'sensual tendency' and 'pragmatic tendency' reflecting the nature of the items classified. Each of four factors of experience perception are named 'pleasure', 'aesthetic', 'superiority' and 'escape'.

From the repetitive tries of variables' entry and removal, the model formed was meaningful. The relationship between experience pursuing tendency and experience perception is significant for sensual tendency to pleasure, aesthetic and escape while pragmatic tendency to superiority. It is very meaningful that two parts of experience pursuing tendency have effects on two different parts of experience perception. Each part of dependent variable has effect on only one part of dependent variables not other side or not complexly with cross. These results confirmed also the results of previous studies on this subject. Generally sensual characteristics have connection with emotional or affective states and functional feature in on rational thinking. Perception for experience is very much kind of both side, cognition and affection of which experience could be considered not separated. The result exposes that specific fields of experience perception need to be identified and for consumers, what consumers in terms of experience pursuing tendency want what exact experience perception. At least from this result, it is effective that sensual pursuers for experience are more appealed to aesthetics, pleasure and escape experience whereas pragmatic pursuers want rather general and traditional experience.

Accordingly, it is concluded that experience pursuing tendency has effects on experience perception after product/service consumption.: (proposition 1)

Table 06: Regression Analysis of Experience Pursuing Tendency and Experience Perception

\begin{tabular}{|c|c|c|c|c|c|c|c|}
\hline \multirow{2}{*}{$\begin{array}{l}\text { experience pursuing } \\
\text { tendency }\end{array}$} & \multirow{2}{*}{$\begin{array}{l}\text { experience } \\
\text { perception }\end{array}$} & \multicolumn{2}{|c|}{ regression analysis } & \multicolumn{2}{|c|}{ model summary } & \multicolumn{2}{|c|}{ multicollinearity } \\
\hline & & beta & $\mathrm{t}$ & $\mathrm{R}^{2}$ & $\mathrm{~F}$ & tolerance & VIF \\
\hline sensual tendency & & .15 & $3.38^{*}$ & & & 1.00 & 1.00 \\
\hline $\begin{array}{l}\text { pragmatic } \\
\text { tendency }\end{array}$ & pleasure & - & - & .030 & $11.44^{*}$ & - & - \\
\hline sensual tendency & & .34 & $7.78^{*}$ & & & 1.00 & 1.00 \\
\hline $\begin{array}{l}\text { pragmatic } \\
\text { tendency }\end{array}$ & aesthetic & - & - & .140 & $60.50^{*}$ & - & - \\
\hline sensual tendency & & - & - & & & - & - \\
\hline $\begin{array}{l}\text { pragmatic } \\
\text { tendency }\end{array}$ & superiority & .16 & $3.28^{*}$ & .025 & $10.65^{*}$ & 1.00 & 1.00 \\
\hline $\begin{array}{l}\text { sensual tendency } \\
\text { pragmatic }\end{array}$ & escape & .15 & $\begin{array}{r}2.75^{*} \\
-\end{array}$ & .017 & $7.57^{*}$ & 1.00 & 1.00 \\
\hline
\end{tabular}


tendency

* Significant under 0.01 .

\subsection{Expertise's and demographics' moderating roles}

The data on consumption expertise, that is, direct experience was collected from the numbers of the use, the consumption or the visit of the product, the service or the place which is most memorable for them among of which consumers have used consumed or visited within recent 3 months. The numbers were grouped into 3 categories of high(over 5), medium(3 4) and low(1 2) depending on numbers. Each group has been adjusted to have approximately same ratio of cases. Regrouping from the original data is to find clearly relationships between variables. The data on Indirect experience was also regrouped into 3 groups, high(4.33 5), medium(3 4) and low(1 2.67) in the same way. Multiregression analyses have been performed using dummy variables for the two variables and low group was used for base, high and medium groups are used with dummys(indiret experience: $\operatorname{high}(d 2=1)$, medium(d1=1), direct experience: $\operatorname{high}(d 4=1)$, medium(d3=1)). Two variables were analyzed for the moderating effects on the relationship of independent variables, experience pursuing tendency and dependent variables, experience perception.

Table 07: Sex demographics' Moderating Effect

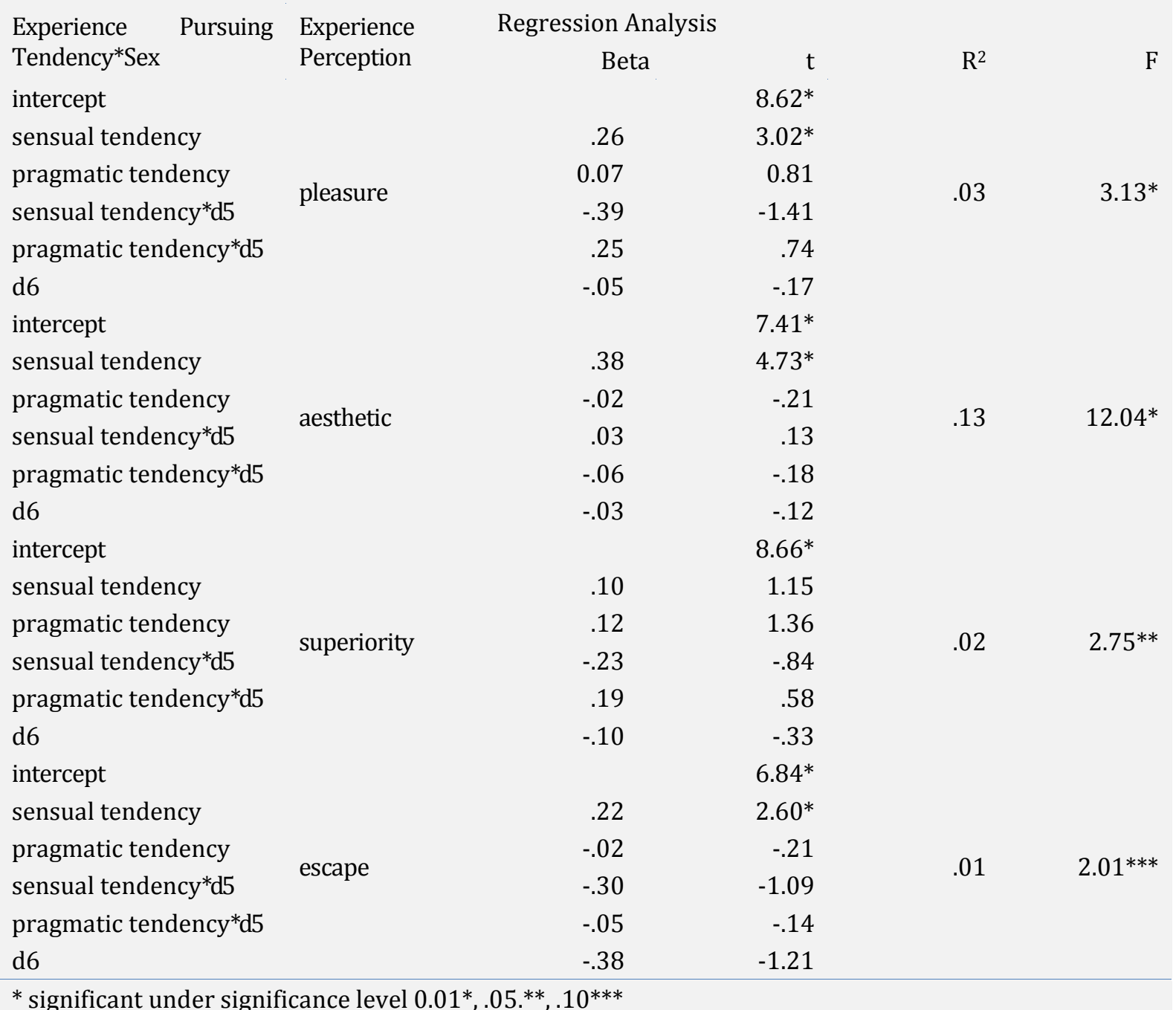

* significant under significance level $0.01^{*}, .05{ }^{* *}, .10^{* * *}$

Table 08: Age_Demographics' Moderating Effect

\begin{tabular}{llrrrr}
\hline Experience Pursuing & Experience & \multicolumn{2}{c}{ Regression Analysis } & & \\
Tendency*Age & Perception & beta & $\mathrm{t}$ & $\mathrm{R} 2$ & $\mathrm{~F}$ \\
\hline intercept & & 2.93 & $16.04^{*}$ & & \\
d10 & pleasure & -.46 & $-3.75^{*}$ & .07 & $9.32^{*}$ \\
sensual tendency & & .14 & $3.15^{*}$ & & \\
\hline
\end{tabular}




\begin{tabular}{|c|c|c|c|c|c|}
\hline sensual tendency*d9 & & -.05 & $-2.00 * *$ & & \\
\hline intercept & & 2.36 & $13.64^{*}$ & & \\
\hline sensual tendency & aesthetic & .33 & $7.78^{*}$ & .016 & $34.13^{*}$ \\
\hline sensual tendency*d10 & & -.80 & $-2.61^{*}$ & & \\
\hline intercept & & 2.68 & $13.08^{*}$ & & \\
\hline pragmatic tendency & superiority & .16 & $3.37^{*}$ & .04 & $7.50^{*}$ \\
\hline sensual tendency*d10 & & -.06 & $-2.06^{* *}$ & & \\
\hline
\end{tabular}

For deduction of model by independent variables and dependent variables with moderators, stepwise method was used. The research model was selected among models that were composed of significant variables with deletion of insignificant variables. But result was different from the proposition 2 that the relationship of experience pursuing tendency and experience perception were not supposed to be affected either by direct or indirect experience of consumption expertise.

Consequently, in the relationship of experience pursuing tendency and experience perception, consumption expertise either direct experience or indirect experience has no moderating effects.: (proposition 2)

This research selected two variables they are sex and age as demographics. Sex and age variables were also used with dummy variables before multiregression analysis. Age variable used four dummies, $10 \mathrm{~s}$ as a base, 20s (d7=1), 30 s $(d 8=1), 40 s(d 9=1)$, and over $50 s(d 10=1)$. Sexes are two groups that they are used as female $(d 5=1)$ and male $(\mathrm{d} 6=1)$. Multiregression analysis with moderating variables, age and sex was carried out likewise the way for the prior analysis. First, the moderating effect of sex was not found to the relationship of experience pursuing tendency and experience perception. And variable's significance was not found to the dependent variables. Only for the perception on aesthetic experience, the model was significant with inclusion of all variables, but other variables were not significant on their beta coefficient $\left(\mathrm{R} 2=.15, \mathrm{~F}=5.84^{*}\right)$, constant coefficient $\left(\mathrm{t}=.05^{* *}\right)$.

The moderating effects of age were found in various ways on the relationship of experience pursuing tendency and experience perception. Experience perception has been affected by the experience pursuing tendency. Its' effects are different depending on the age. Significant model only in the experience perception of escape was not found among models of the relationship of independent and dependent variables including moderating variable of age. But pleasure, aesthetics, and superiority of experience perception have effects from the moderating variable of age.

Age has effects only on pleasure of experience perception individually specially at over 50 s. And over 40 s especially over 50s plays negative role on pleasure of experience perception. As investigating three models on experience perception, sensual tendency of experience pursuing tendency is effective to pleasure and aesthetic experience perceptions individually and also with interaction of age. Superiority has been affected by pragmatic tendency individually and with interaction of age by sensual tendency. On the modeling, the effects of 40 s and over 50 s are dominant and negative to experience perception.

Let these relationships schematized as follows.

pleasure: $\mathrm{y}^{\wedge}=2.93-.46 \mathrm{~d} 10+.14$ SEN-.05SENd9

aesthetic: $\mathrm{y}^{\wedge}=2.36+.33 \mathrm{SEN}-.80 \mathrm{~d} 10$

superiority: $\mathrm{y}^{\wedge}=2.68+.16 \mathrm{PRA}-.06 \mathrm{SENd} 10$

As calculating the schematic diagram above, pleasure is perceived by a similar level through $10 \mathrm{~s}$ to $30 \mathrm{~s}$ (3.08 respectively). But pleasure is perceived by a lower level to 40s (2.92) and over 50s (2.47). Pursuers of sensual stimulation are worse in perceiving experience. For the aesthetics of experience perception, 10s through 40s (2.69 respectively) are responding similarly, over 50s(1.89) perceived lower than other age groups. Likewise the other categories of experience perception, superiority is shown in a low level for the group of over 50s (2.79) rather than other age groups (2.84 respectively). As the people of over 50s, they face various different circumstances in their families and in themselves like personal health and climacteric changes, and change in lifestyle, retirement and family members. These changing conditions might let them perceive experience less sensitively or negatively. The results suppose that perception for experience decreases and specific aspects of experience perception are changing with age.

Meanwhile, escape of experience perception was not found in the relationship of experience pursuing tendency with the interaction of age. As the aspect of experience perception, the stronger sensual tendency the higher escape perceived. 
From the results, the relationships of consumers' experience pursuing tendency and experience perception are different with the moderating role of demographics: (proposition 3)

\subsection{Conclusion}

Sustaining and increasing preference for experiential goods and experiential aspects of consumption caught on academics' and practitioners' interests. Now consideration should be on more deep in specific areas and at the same time all in aspects of experience. Consumers' experience pursuing tendency and consumers' expertise on consumption as consumers' personality traits are drawn on the side of internal characteristics of consumers and demographics were drawn as external characteristics. Consumers' internal and external aspects with the relationship of experience perception are meaningful on this subject.

This study examined the relationship of consumers' experience pursing tendency and experience perception with the moderating role of consumers' expertise, direct and indirect experience and their demographics, sex and age. Final results show that there are relationships between consumers' experience pursuing tendency and experience perception, sensual pursuers tend to perceive emotional dimensions of experience even more than pragmatic pursuers do. The pursuers more practical are not susceptible to emotional experience but positively to professional experience. Knowledge accumulated by indirectly and directly does not control the relationship between experience pursuing tendency and experience perception. But sex and age as demographic variables are involving the relationships between them. Aged consumers, over 50s conspicuously perceived experience less, especially to the emotional side of experience perception. From the results of the study managerial and research implications could be presented as follows.

The management of experience should be followed by the consumers' experience pursuing tendency. Emotional aspects among the experience perception have been affected by the pursuers of sensual stimulation while rational experience perception is controlled by general and traditional pursuers. Experience perception is separated into two sides by the personal traits, experience pursuing tendency. That means experience should be managed depending on the personal traits, experience pursuing tendency. The dimension of experience, emotional perception need to more intensified to sensual pursuers in terms of advertising, product design, atmosphere of stores or shops, manner of service for the workers and so on. But traditional or general experience separated from emotional needs to dealt to be differently. General and steady change would be preferred to consumers. Comparing to expenses for new designs and changes for product, service or shops, offsetting revenue could be earned. These people, pragmatic pursuers can be served as market segment at the same times and lagged consumers to sensual pursuers with times.

Consumption expertise from direct and indirect experience was not found as considerable factors for experience management. And sex is not found either as a special factor to be considered to manage experience. With more refined research designs, these variables should be investigated with the subject of experience perception in other researches.

Important findings in age were held with the relationships of experience pursuing tendency and experience perception. Experience should be dealt with age. As getting older, consumers are less sensitive to perception of experience even for the sensual pursuers. Sensual pursuers are more positively responding to aesthetics and pleasure but the pragmatic pursuers are perceiving superiority of experience. Aesthetic experience needs to expanded for older people rather than experience, pleasure. Art elements, music, well prepared circumstances of consumption could induce sensual pursuers and over 50s of sensual tendency. Parks, classic concerts, fine and detail shopping stores, museums, banks and so on are attractive to them. Accordingly depending on the experience pursuing tendency and age, experience should be designed properly and differently.

\section{References}

Alba J. W., J. Wesley Hutchinson, (1987). Dimensions of Consumer Expertise. Journal of Consumer Research, 13(4): 411-454.

Bei L.T., R. Widdows, (1999). Product Knowledge and Product Involvement as Moderators of the Effects of Information on Purchase Decisions: A Case Study Using the Perfect Information Frontier Approach. The Journal of Consumer Affairs, 33(1): 165-186.

Corporate Univ. Review, (2001). Don't Sell Commodities, Sell Experience. Reinventing business, Mar./Apr., 9(2): 22.

Hoch S.J., (2002). Product Experience is Seductive. Journal of Consumer Research, 20(Dec.): 448-454.

Holbrook M.B., E.C. Hirschman, (1982). The experiential Aspects of Consumption: Consumer Fantasies, Feelings, 
and Fun. Journal of Consumer Research, 9(2): 132-140.

Kerr J. H., (1991). Arousal Seeking in Risk Sport Participants. Personality and Individual Differences, 12(6): 613616.

McDanniel S.R., M. Zuckerman, (2003). Personality across instruments and observers. Personality and Individual Differences, 35: 1385-1400.

Mehrabian A., J.A. Russell, (1976). Environmental Variables in Consumer Research. Journal of Consumer Research, $3(1): 62-64$.

Mehmetoglu M., (2012). Personality effects on experiential consumption. Personality and Individual Differences, 52: 94-99.

Neuborne E., (2001). Happy Returns. Business Week, 8(Oct.): SB 16.

Noh J.G., S.J. Kim, (2002). The effect of the stimulus pursuit tendency and the ego identity status on the adolescence's attitude about shoplifting. Journal of Marketing Management Research, 7(3): 155-176.

Pine B.J. II, J.H. Gilmore, (1998). Welcome to the Experience Economy, Harvard Business Review, July/Aug.: 97105.

Pine II B.J., J.H. Gilmore, (1999). The Experience Economy: Work Is Theater \& Every Business a Stage. Boston, MA: Harvard Business Press.

Pizam A., A. Reichel, N. Uriely. (2002). Sensation seeking and tourist behavior. Journal of Hospitality and Leisure Marketing, 9(3/4): 17-33.

Rosa J.A., A.J. Malter, (2003). E-(Embodied) Knowledge and E-Commerce: How Physiological Factors Affect Online Sales of Experiential Products. Journal of Consumer Psychology, 13(1\&2): 73-73.

Schmitt B., (1999). Experiential Marketing. Journal of Marketing Management, 15: 53-67.

Srinivasan S.R., R. K. Srivastava, (2010). Creating the futuristic retail experience through experiential marketing: Is it possible? An exploratory study. Journal of Retail \& Leisure Property, 9(3): 193-199.

Thomson M., D.B. MacInnis, C.W. Park, (2005). The Ties That Bind: Measuring the Strength of Consumers' Emotional Attachments to Brands. Journal of Consumer Psychology, 15(1): 77-91.

Zuckerman M., (1978). Sensation Seeking: The Biological need for high stimulation. Psychology Today, 38-49.

Zuckerman M., (1979). Sensation seeking: beyond the optimal level of arousal. Lawrence Erlbaum Associates, Hillsdale, N. J.

Zuckerman M., (1984). Sensation Seeking: A Comparative Approach to Human Trait. The Behavioral and Brain Sciences, 7: 413-71.

Zuckerman M., M. Neeb, (1980). Demographic influences in sensation seeking and expression seeking in religion, smoking and driving habits. Personality and Individual Differences, 1: 197-206.

Zuckerman M., M.S. Buchsbaum, D.L. Murphy, (1980). Sensation Seeking and its Biological Correlates. Psychological Bulletin, 88: 187-214. 